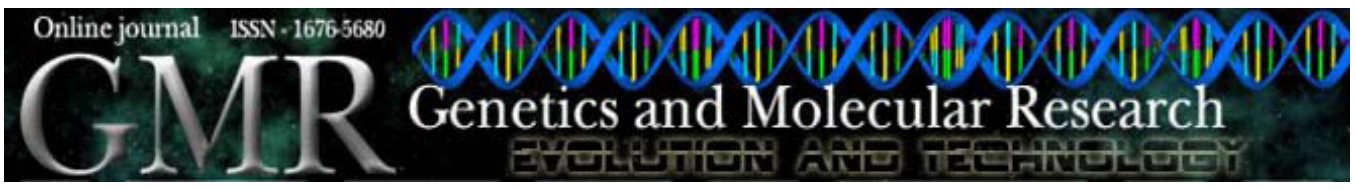

\title{
RAPD identification of Varroa destructor genotypes in Brazil and other regions of the Americas
}

\author{
J.C.V. Guerra Jr. ${ }^{1}$, M.R.C. Issa ${ }^{2}$, F.E. Carneiro ${ }^{1}$, R. Strapazzon ${ }^{1}$ and \\ G. Moretto ${ }^{1}$ \\ ${ }^{1}$ Departamento de Ciências Naturais, \\ Universidade Regional de Blumenau, Blumenau, SC, Brasil \\ ${ }^{2}$ Departamento de Biologia, \\ Faculdade de Filosofia Ciências e Letras de Ribeirão Preto, \\ Universidade de São Paulo, Ribeirão Preto, SP, Brasil \\ Corresponding author: J.C.V. Guerra Jr. \\ E-mail: jcguerra@furb.br
}

Genet. Mol. Res. 9 (1): 303-308 (2010)

Received September 17, 2009

Accepted November 17, 2009

Published February 23, 2010

\begin{abstract}
The mite Varroa destructor is the main pest causing damage to apiculture worldwide. In Brazil and other parts of the world, where bees of African origin and their hybrids predominate, the bees can survive these mites without treatment. Studies have shown a correlation between the various genotypes of the mite and its fertility in different geographical regions. Information about mite genotype could be helpful in understanding the diverse effects and relationships of the mite with bees in different regions of the world. DNA analysis by RAPD technique has permitted identification of three distinct genotypes in the mite $V$. destructor, namely Russian, Japanese and Papua New Guinea. We found predominance of the Russian genotype in Brazil, along with other parts
\end{abstract}


of South America, and in Cuba and Mexico. The Japanese genotype was exclusively found on Fernando de Noronha Island in Brazil.

Key words: RAPD; Varroa destructor; Resistance; Genotype

\section{INTRODUCTION}

Varroa destructor mite, an ectoparasite of Apis cerana and Apis mellifera honey bees, is the main pest responsible for problems in apiculture. However, the intensity of damage caused by Varroa mites has been shown to vary according to the region studied. In Brazil and other parts of the world, where bees of African origin and their hybrids predominate, a perfect relationship exists between the parasite and its host. However, it is unknown whether the severity of the effects caused by the Varroa parasite depends on the genotype of the bees and/or on the genotype of the mite. Evidence suggests that the mite $V$. destructor is a complex species. Studies have shown a correlation between the various genotypes of the mite and its fertility in different geographical regions (de Guzman and Rinderer, 1999). This information could be helpful in understanding the diverse effects and relationships of the mite with bees in different regions of the world.

DNA analysis by the randomly amplified polymorphic DNA (RAPD) technique has permitted a more precise study of the genetic variability among mite populations (Kraus and Hunt, 1995), and has led to the identification of three distinct genotypes of the mite $V$. destructor: Russian (R), Japanese (J) and Papua New Guinea (PNG) (de Guzman et al., 1997; Anderson and Fuchs, 1998). In a previous study, Kraus and Hunt (1995), using the RAPD technique, identified bands that are common to mites from Germany and the United States, but are absent in mites from Malaysia. Using the OPE-07 primer, the R genotype has been characterized by the presence of a 766-bp band, which is absent in mites with the J genotype (de Guzman and Rinderer, 1999). The use of the OPP-03 primer permitted the detection of a 442-bp band characterizing the R genotype. Genotype J does not possess this band but produces two distinct bands of 675 and $412 \mathrm{bp}$, which are absent in the R genotype.

Worldwide differences in the infestation of A. mellifera bees with the mite $V$. destructor suggest a correlation between some genotypes and a higher or lower virulence of the mite. DNA analyses have revealed variable $V$. destructor genotypes infesting $A$. mellifera and A. cerana in Asia (de Guzman et al., 1997; Anderson and Fuchs, 1998). A low virulence of the PNG genotype has been well documented in Papua New Guinea and Indonesia (Anderson and Fuchs, 1998). In contrast, marked losses of A. mellifera colonies are observed in countries in which the R genotype occurs, such as the Philippines and Korea (Cervancia, 1993). In Vietnam, the mite $V$. destructor represents the main agent causing damage to apiculture, with $A$. mellifera colonies harboring mites with the R genotype, while $A$. cerana colonies harbor mites with the J genotype (de Guzman and Rinderer, 1998). This finding may be explained by the differential reproduction of the mite in A. mellifera and $A$. cerana colonies, as observed in Japan, where only the J genotype (de Guzman et al., 1997) and the two bee species exist (A. mellifera and A. cerana) and where no loss of colonies has been observed since 1970 (Yoshida, cited in de Guzman and Rinderer, 1999).

Studies showed a worldwide distribution of the R genotype, including Europe, United States, Mexico, and Argentina, while the J genotype is restricted to Japan, Brazil, Puerto Rico, and some states in the United States (de Guzman et al., 1997). However, in the specific case of Brazil, analyses have been based on mites sampled only from apiaries in Rio 
de Janeiro State in 1990 and 1993. Therefore, the study of mites from various other regions of Brazil, mainly the south region (Rio Grande do Sul and Santa Catarina), could reveal the presence of the R genotype also in Brazil, especially considering the proximity to Argentina (R genotype). The importation of European queens from the United States, Europe and Argentina by Brazilian beekeepers and proximal geographical contact with Argentina (natural swarm dispersion) itself could have been two ways for this genotype to arrive in Brazil.

\section{MATERIAL AND METHODS}

Polymorphic RAPD-type DNA markers were used to determine the genotypes of $V$. destructor mites originating from different localities in Brazil and from other American countries.

Samples of $V$. destructor from 5 States of Brazil were analyzed: Santa Catarina $(\mathrm{N}=$ 20), São Paulo $(N=20)$, Minas Gerais $(N=10)$, Rio Grande do Norte $(N=10)$, Amazonas $(\mathrm{N}=8)$, and Fernando de Noronha Island - $\mathrm{PE}(\mathrm{N}=10)$. Other varroa mites from American countries were also sampled: Argentina $(\mathrm{N}=20)$, Venezuela $(\mathrm{N}=10)$, Cuba $(\mathrm{N}=7)$, Chile $(\mathrm{N}=10)$, Uruguay $(\mathrm{N}=15)$, Colombia $(\mathrm{N}=5)$, and Mexico $(\mathrm{N}=15)$.

Female adult mites were used for DNA analysis. The mites were collected from worker and/or drone broods and immediately transferred to $70 \%$ alcohol. In the laboratory, the mites were removed from the alcohol, dried and stored in a freezer at $-20^{\circ} \mathrm{C}$.

Total DNA was extracted individually from each female of $V$. destructor using the fast method adapted from Anderson and Fuchs (1998). After washing in $70 \%$ ethanol, the mite was transferred to a microcentrifuge tube containing $40 \mu \mathrm{L} 2 \mathrm{X}$ lysis buffer $(120 \mu \mathrm{g} / \mathrm{mL}$ proteinase $\mathrm{K}, 0.1 \mathrm{M} \mathrm{KCl}, 0.02 \mathrm{M}$ Tris-HCl, $\mathrm{pH} 8,3.5 \mathrm{mM} \mathrm{MgCl}, 0.9 \%$ Tween $20,0.9 \% \mathrm{NP} 40$ and $0.02 \%$ gelatin), which was incubated first at $65^{\circ} \mathrm{C}$ for $30 \mathrm{~min}$, and $95-100^{\circ} \mathrm{C}$ for $10 \mathrm{~min}$, and finally, the content was diluted with $\mathrm{dH}_{2} \mathrm{O}$.

The primer OPE-07 ( $5{ }^{\prime 2}$ AGA TGC AGC C 3') (Kraus and Hunt, 1995) was used for DNA amplification and to detect the R and J genotypes.

The samples were prepared for amplification in a volume of $10 \mu \mathrm{L}$ (Kraus and Hunt, 1995; modified). The reaction mix contained $10 \mathrm{mM}$ Tris- $\mathrm{HCl}, 50 \mathrm{mM} \mathrm{KCl}, 2 \mathrm{mM} \mathrm{MgCl}, 0.1$ $\mathrm{mM}$ of each dNTP, $0.2 \mu \mathrm{M}$ of the primer, $0.5 \mathrm{U}$ Taq polymerase, and $1.5 \mu \mathrm{L}$ of the extracted DNA. The amplification reaction consisted of 48 cycles of $1 \mathrm{~min}$ at $94^{\circ} \mathrm{C}, 1 \mathrm{~min}$ at $35^{\circ} \mathrm{C}$, and 2 min at $72^{\circ} \mathrm{C}$. The products were submitted to $1 \%$ agarose gel electrophoresis and stained with ethidium bromide (Maniatis et al., 1982). The gels were visualized and photographed under UV light (Doc-Print, Sony and Biosystem Apparatus), and the amplification products were identified using the $\phi \mathrm{X} 174 \mathrm{RF}$ DNA/HaeIII marker (Invitrogen).

\section{RESULTS AND DISCUSSION}

Figure 1 shows the different genotype patterns determined in this study. All samples from Fernando de Noronha Island (Pernambuco State, Brazil) showed the J pattern. Analysis of mites from the southern region of Brazil (Santa Catarina) and other regions (Amazonas, São Paulo, Minas Gerais, and Rio Grande do Norte) showed the R pattern. Mites from other American countries (Argentina, Uruguay, Colombia, Cuba, Chile, and Mexico) also showed only the R genotype. 


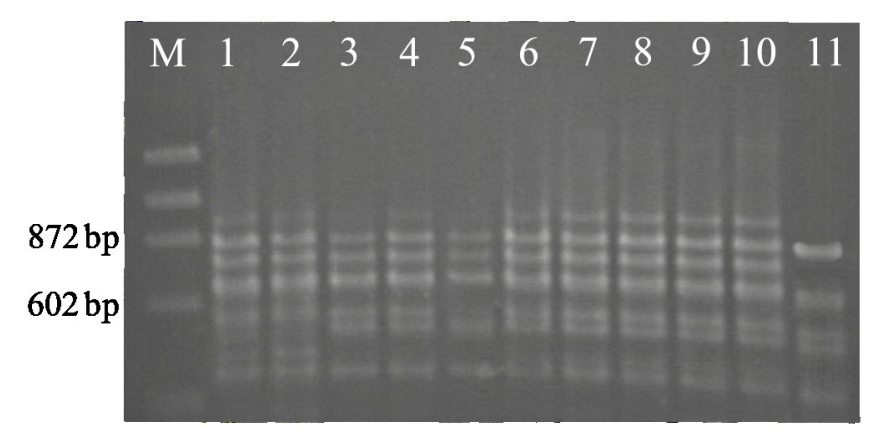

Figure 1. Agarose gel (1.0\%) showing the different banding patterns observed among Varroa destructor from different regions of Brazil and American countries using the primer OPE-07. M = Molecular weight marker $\phi X 174$ RF DNA/HaeIII. Lane 1 = Santa Catarina; lane 2 = São Paulo; lane 3 = Minas Gerais; lane $4=$ Amazonas; lane $5=$ Rio Grande do Norte; lane $6=$ Argentina; lane $7=$ Venezuela; lane $8=\mathrm{Cuba}$; lane $9=$ Uruguay; lane $10=$ Mexico; lane 11 = Fernando de Noronha Island.

The results confirmed the initial hypothesis of the study that the $\mathrm{R}$ genotype was already present not only in the south but also in the southeast, northeast (except Fernando de Noronha Island) and north region of Brazil as well as other countries examined, with mites showing the same genetic pattern (RAPD) as that found in Argentina, Canada and United States (de Guzman and Rinderer, 1998).

As there is no barrier to the dispersion of the varroa in all the continental part of Brazil, the increase in the reproductive ability of the mite corroborates with the hypothesis of genotype substitution occurring over time. This hypothesis is reinforced by the presence of the J genotype on Fernando de Noronha Island. The Italian bees were introduced on this island in 1984, when some colonies of bees with imported Italian queens (Apis mellifera ligustica) of the United States had been taken from Ribeirão Preto, State of São Paulo, to this island (Malagodi et al., 1986). Therefore, the geographic isolation must explain the exclusive occurrence of the J genotype on Fernando de Noronha Island.

Mites continue to expand throughout the world and the constant changes in the world (collective apiculture) may lead to new crossing opportunities for mites of different origins. New combinations of genetic markers provide evidence for this hybridization, as already observed in some regions of the United States and Canada with the occurrence of the two genotypes R and J in the same bee colony (de Guzman and Rinderer, 1999). This event was also examined in the present study, and our results do not indicate the presence of the two $V$. destructor genotypes in the same Africanized bee colony.

Using mitochondrial markers, Garrido et al. (2003) determined the relationship between fertility and haplotype in a study of Varroa destructor mites sampled from colonies of A. mellifera carnica and Africanized honey bees (Apis mellifera) in Germany and Brazil, respectively. Both in Germany and in Brazil, only the V. destructor Korea haplotype was found, though the Japan-Thailand haplotype was previously thought to have been more abundant in Brazil (Anderson, 2000; Anderson and Trueman, 2000).

The fertility of Varroa mites in Brazil has increased to European levels. In 1986-1987, only $35 \%$ of the varroa females that invaded worker broods had left at the least one viable 
descendant, compared to $72 \%$ in 2005-2006 (Carneiro et al., 2007).

It is unknown whether the severity of the effects caused by the Varroa parasite depends on the genotype of the bees and/or on the genotype of the mite. Evidence suggests that the mite $V$. destructor is a complex species (Kraus and Hunt, 1995; de Guzman et al., 1997; Anderson and Fuchs, 1998; Anderson, 2000; Anderson and Trueman, 2000).

Studies have shown a correlation between the various genotypes of the mite and its fertility in different geographical regions (Garrido et al., 2003). This information may be helpful in understanding the diverse effects and relationships of the mite with bees in different regions of the world. DNA analysis by the RAPD and mtDNA techniques has permitted a precise study of genetic variability among mite populations.

However, the temporal changes in mite fertility and genotype (RAPD), haplotype (mtDNA) that occur in Brazil are not fully correlated with the increasing infestation levels observed at the moment. Other mechanisms limiting mite populations include removal of brood infested with Varroa (hygienic behavior) (Guerra Jr. et al., 2000), mite mortality in adult bees (Correa-Marques et al., 2002; Moretto, 2002) and mortality of mite offspring (Mondragón et al., 2006). These factors among others determine the tolerance of these bees to the mite Varroa destructor and keep the levels of infestation in Brazil low. It is not known if the substitution and/or genetic alteration of genotype (RAPD) and haplotype (mtDNA) is recent. Although the infestation levels of Varroa destructor in Brazil are low, a monitoring program is very important.

\section{ACKNOWLEDGMENTS}

The authors thank David de Jong, María Alejandra Palacio, Jorge Tello Duran, Dejair Message, Miguel Neira, and Luis Medina Medina for samples of the mites; Zilá L. Paulino Simões for her laboratorial support, and Vera Lucia Castelo Figueiredo for technical assistance.

\section{REFERENCES}

Anderson DL (2000). Variation in the parasitic bee mite Varroa jacobsoni Oud. Apidologie 31: 281-292.

Anderson DL and Fuchs S (1998). Two genetically distinct populations of Varroa jacobsoni with contrasting reproductive abilities on Apis mellifera. J. Apic. Res. 37: 69-78.

Anderson DL and Trueman JW (2000). Varroa jacobsoni (Acari: Varroidae) is more than one species. Exp. Appl. Acarol. 24: $165-189$.

Carneiro FE, Torres RR, Strapazzon R, Ramírez SA, et al. (2007). Changes in the reproductive ability of the mite Varroa destructor (Anderson \& Trueman) in Africanized honey bees (Apis mellifera L.) (Hymenoptera: Apidae) colonies in southern Brazil. Neotrop. Entomol. 36: 949-952.

Cervancia CR (1993). Philippines Beekeeping Status of Research and Development. In: Beenet Asia: Workshop on Priorities in R\&D on Beekeeping in Tropical Asia, Kuala Lampur, 49-63. Available at [http://webdb.stii.dost.gov. $\mathrm{ph} /$ scidetails.jsp?sci_id $=000298]$.

Correa-Marques MH, De Jong D, Rosenkranz P and Goncalves LS (2002). Varroa-tolerant Italian honey bees introduced from Brazil were not more efficient in defending themselves against the mite Varroa destructor than Carniolan bees in Germany. Genet. Mol. Res. 1: 153-158.

de Guzman LI and Rinderer TE (1998). Distribution of the Japanese and Russian genotypes of Varroa jacobsoni. Honeybee Sci. 19: 115-119.

de Guzman LI and Rinderer TE (1999). Identification and comparison of Varroa species infesting honey bees. Apidologie 30: 85-95.

de Guzman LI, Rinderer TE and Stelzer JA (1997). DNA evidence of the origin of Varroa jacobsoni Oudemans in the Americas. Biochem. Genet. 35: 327-335.

Garrido C, Rosenkranz P, Paxton RJ and Gonçalves LS (2003). Temporal changes in Varroa destructor fertility and 
haplotype in Brazil. Apidologie 34: 535-541.

Guerra JCV Jr., Gonçalves LS and De Jong D (2000). Africanized honey bees (Apis mellifera L.) are more efficient at removing worker brood artificially infested with the parasitic mite Varroa jacobsoni Oudemans than are Italian bees or Italian/Africanized hybrids. Genet. Mol. Biol. 23: 89-92.

Kraus, B and Hunt G (1995). Differentiation of Varroa jacobsoni Oud. populations by random amplification of polymorphic DNA (RAPD). Apidologie 26: 283-290.

Malagodi M, Kerr WE and Soares AEE (1986). Introdução de abelhas na ilha de Fernando de Noronha. Cienc. Cult. 38: 1700-1704.

Maniatis T, Fritsch EF and Sambrook J (1982). Molecular Cloning: A Laboratory Manual. Cold Spring Harbor Laboratory, Cold Spring Harbor.

Mondragón L, Martin S and Vandame R (2006). Mortality of mite offspring: a major component of Varroa destructor resistance in a population of Africanized bees. Apidologie 37: 67-74.

Moretto G (2002). Mortality of varroa destructor in broodless Africanized and Carnica honey bee (Apis mellifera L.) colonies. Interciencia 27: 702-704. 